\title{
PRIMER REPORTE DE LA FAMILIA CYRTAUCHENIIDAE (ARANEAE: MYGALOMORPHAE) EN LA FAUNA ACTUAL DE LA HISPANIOLA
}

Giraldo Alayón García, Investigador y Curador de Arácnidos, Museo Nacional de Historia Natural, La Habana,
Cuba. moffly@informed.sld.cu Gabriel de los Santos, Asistente de investigación, Museo Nacional de Historia Natural, Santo Domingo, República Dominicana.g.santos@museohistorianatural.gov.do

\section{ABSTRACT}

The family Cyrtaucheniidae is recorded from the extant fauna of the island of Hispaniola for the first time.

Key words:Mygalomorphae, Cyrtaucheniidae, Haiti, Dominican Republic, ambar, fossil fauna, extant fauna, Hispaniola.

La familia Cyrtaucheniidae se caracteriza por poseer una escópula relativamente densa en el tarso y metatarso I y II; patas anteriores finas con muy pocas espinas dorsales; quelíceros con una sola línea de dientes en el promargen y un pequeño parcho de pequeños dientes en el retromargen; fovea transversa al tórax que es recta, recurva, o procurva; sin tergitos abdominales. Quelíceros sin línea de setas negras parecidas a varillas. Hilanderas posteriores laterales de longitud intermedia. Viven en agujeros con una pequeña torre flexible en la entrada (Apomastus), o una fina puerta de seda -las demás especies- (traducido de Bond, 2005).

El conocimiento que se tiene acerca de la aracnofauna de La Hispaniola (República Dominicana y Haití) es pobre. Hasta la fecha, se han reportado 322 especies actuales y 188 fósiles. En cuanto a los migalomorfos, solo se han reportado 16 especies (incluyendo 6 fósiles) agrupadas en 5 familias -tres actuales y dos fósiles- (Perez-Gelabert, 2008); de las 10 especies actuales, 7 son endémicas. La especie Bolostromus destructus Wunderlich, 1988, descrita del ámbar dominicano, es la única especie que se conoce de la familia Cyrtaucheniidae en La Hispaniola (vease, Penney y Perez-Gelabert, 2002). Esta nota reporta por primera vez la presencia de la familia Cyrtaucheniidae en la fauna actual de La Hispaniola.

El primer ejemplar de esta familia, juvenil, fue colectado en Camino de Playa Frontón, Provincia Samaná, el 7 de diciembre del 2007; posteriormente, en el 2008 se colectaron seis especímenes más en la localidad de El Matadero, Provincia Peravia, en la parte sur de la República Dominicana. En el último viaje realizado a esta última localidad, se encontraron tres madrigueras típicas (Fig. 1a) en un área menor a $1 \mathrm{~m}^{2}$; y cinco de estos seis especímenes han sido colectados en un área menor a los $30 \mathrm{~m}^{2}$. Todos los ejemplares colectados pertenecen al género Bolostromus Ausserer, 1875, el cual presenta dos especies en Las Antillas: B. insularis (Simon, 1891) de San Vicente y B. holguinensis Rudloff, 1996 de Cuba, esta última especie parece muy cercana a la encontrada en República Dominicana.

Finalmente, agradecemos a Miguel A. Landestoy por las fotografías.

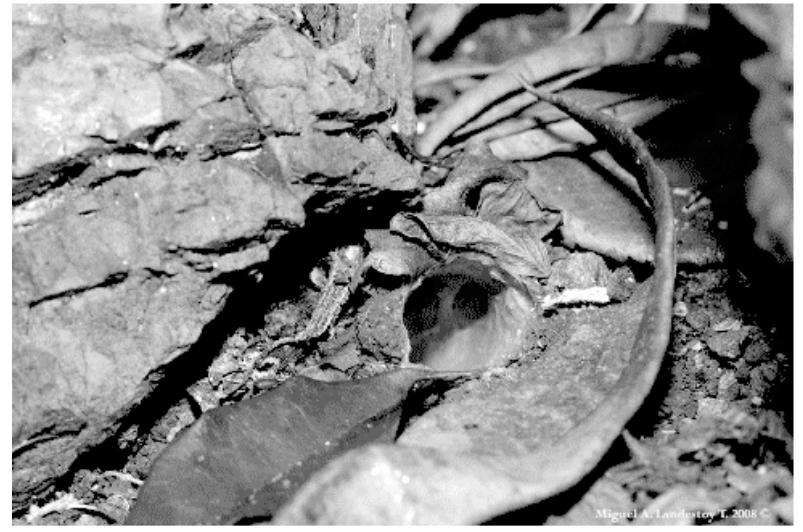

$1 \mathbf{a}$

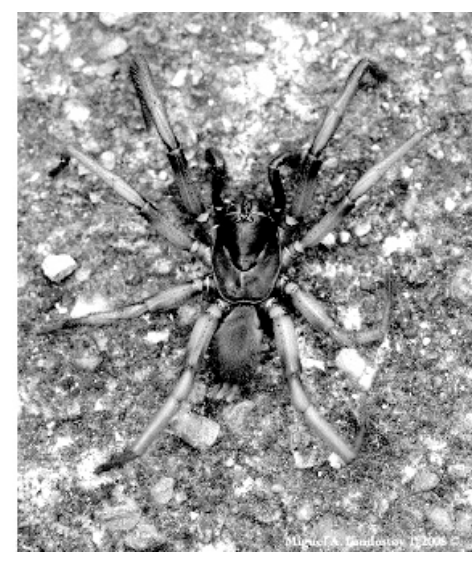

$1 b$

Figura 1: 1a. Entrada de la madriguera; 1b. vista dorsal de uno de los machos colectados. 


\section{LITERATURA CITADA}

Bond, J. E. 2005. Cyrtaucheniidae. p. 45 en D. Ubick, P. Paquin, P. E. Cushing, y V. Roth (eds.). Spiders of North America: an identification manual. American Arachnological Society.

Penney, D. y D.E. Perez-Gelabert. 2002 Comparison of the Recent and Miocene Hispaniolan spider faunas. Revista Ibérica de Aracnología, 6, 203223.

Perez-Gelabert, D. E. 2008. Arthropods of Hispaniola (Dominican Republic and Haiti): A checklist and bibliography. Zootaxa, 1831, 1-530. 